\title{
Creativity and innovation in social work practice and research
}

This edition of the Aotearoa New Zealand Social Work journal is dedicated to celebrating creativity and innovation in practice and research. We were pleased to receive a good number of submissions for this special edition demonstrating that both resourcefulness and inspiration are alive and well in our discipline. In fact, it is notable that even while practitioners and researchers are still operating within the constraints of a neoliberal market driven economy they have still been able to find places and spaces to exercise diverse ways to innovate and create.

We know that creativity is part of the human condition and has associations with playfulness, fluid and flexible thinking. These attributes are often in tension with the daily realities of practice where issues of compliance and pressure of workload management are constant. Within this context some find it hard to engage with creativity, believing instead that only didactic, serious considerations of practice and research are robust. In fact, we know and can demonstrate with the contributions to this special edition that creativity and innovation provide alternative ways for people to express both serious and robust ideas.

The contributions to this special issue demonstrate how creativity and innovation can make a difference at the micro, meso and macro level; examples include: giving voice to people with a chronic health condition; promoting the role of the arts in fostering health and dialogue; exploring options for sustainable community living; advocating for the role of companion animals in disaster planning; and learning about cross-sector partnerships in health service delivery.

The first three articles in this edition showcase innovative research methodology that has enabled service users to offer vivid expressions of their experiences and concerns. Michele Jarldorn, in "Picturing creative approaches to social work", and Bharati Sethi, in "Using the eye of the camera to bare racism" have written about the use of photovoice methodology in their research with ex-prisoners and with migrants seeking employment respectively. Both of these articles include photographs taken by participants in their research.

Photovoice is a method where participants are provided with the means to take photographs that illustrate actual or symbolic features of a participant's narrative, which are followed up by interviews to discuss the photographs as part of the data collection. Both articles include findings from hard to reach populations and evidence how the process of both taking the photographs and talking about them enabled participants to communicate deeply personal experiences.

Jarldorn gives a strong account of how this methodology fits well with social work in terms of its philosophy, practice and research possibilities. She notes however, that despite this good fit, photovoice has been an underutilised research methodology in our discipline. Quite possibly, the emancipatory process fostered by this method presents a challenge to dominant and traditional views about how research ought to be conducted. We found the findings in Sethi's account of her research with migrant women in Canada shocking to read but important to publish. In her research, photovoice methodology starkly captures the themes of isolation and discrimination while at the same time giving voice to this group of women. The very recent report about the exploitation of migrant workers here in New Zealand (Stringer, 2016) signals that similar results to those found by Sethi are evident in the Aotearoa New Zealand context.
AOTEAROA NEW ZEALAND SOCIAL WORK 28(4), 1-4. 
In "The art of body mapping", Michelle Skop details how she used the creative method of body mapping to conduct research with people who have fibromyalgia. Skop provides clear instructions on how to use body mapping in research. Her work also opens up possibilities for practitioners to use this method in both individual and group work with people in diverse circumstances related to health, emotional well-being or identity. The article includes examples of the body maps created by the participants. The social change agenda inherent in social work is overtly addressed in this research with exhibitions of the maps being made available to the public to raise awareness about fibromyalgia as a condition.

The research methodologies reported in these first three articles have been used to address social justice imperatives at micro and meso levels, raising awareness about a particular health condition as well as making visible the challenges experienced by ex-prisoners and migrants workers.

The next set of three articles in this edition show examples of how the arts more broadly can be used constructively in social work to document, heal and inspire. Within this context, we were drawn to an observation by one of the authors in this edition who noted... "Alienation or a 'deadening of the senses' of the oppressed within the capitalist world can be countered, in part, by participation in the arts (Reitz, 2000, p. 15 cited in Jarldorn, this issue)". Further to this observation, we concur with Michalos (2005) that "the impact of the arts broadly construed on the overall quality of people's lives is without a doubt the most understudied and possibly most underrated issue in the field of social indicators research" (p. 12). As such, we are pleased to be able help build a body of knowledge that helps explain some of the existential and lifegiving qualities use of the arts in social work practice can offer.

The following three articles critically discuss the creative and innovative application of arts-based practice methods. Artsbased exploration of human feelings and understandings provides the opportunity to tap into deeper levels of the human experience than written and spoken language alone. In various ways, a powerful case is built for the use of dance, drama, visual and graphic art in meeting the complex challenges of communication which confront contemporary social work practice.

Deborah Espiner and Frances Hartnett explore the synergy between graphic facilitation and empowerment-focussed social work practice in their article "Innovation and graphic facilitation". Graphic facilitation involves the translation of dialogue into visual images; a visual record which can develop and convey meaning in a way that promotes inclusion, ownership and the retention of powerful ideas. The focussing and energising qualities of this approach are illustrated through discussion of its application in person-centred planning and World Café style visioning and planning exercises. Graphic facilitation has the potential to be used in individual, group, community and organisational settings to generate nonlinear and free flowing contributions to discussions and planning.

Yukari Seko and Trish Van Katwyk reflect on the rich experience, as nondancers, of presenting knowledge about self-injury through bodily expression. Findings reported in "Embodied interpretation: Assessing the knowledge produced through a dance-based inquiry" suggest that researchers need to carefully consider the way in which audiences understand arts-based representation. A small amount of introductory information about a sensitive topic like self-injury may sway audience interpretations towards mainstream pre-conceptions. Audience members who were not advised of the topic were more likely to be open to hopeful interpretations less clouded by dominant discourse. 
Amber Walls, Kelsey Deane and Peter O'Connor rigorously explore the evidence base for employing participatory arts programmes in therapeutic youth work, with a particular eye to the under-researched Aotearoa New Zealand context. "Looking for the blue, the yellow, all the colours of the rainbow: The value of participatory arts for young people in social work practice" provides an account of an Auckland-based creative arts participation project evaluated through a focus group process that itself utilises an arts-based expression component. A compelling argument emerges for the funding, development and evaluation of this vibrant practice approach.

The seventh article in this edition challenges social workers to reflect on their identity in the Aotearoa New Zealand's bicultural context. Heidi Crawford's article "A Pākehā journey towards bi-cultural practice through guilt, shame, identity and hope" is an account of her personal journey of understanding and growth. She notes that that shame and guilt in relation to colonisation can act as barriers to competent bi-cultural practice. Crawford demonstrates how making purposeful choices to experience and learn about the Māori world can lead to social workers towards "bicultural wisdom" (Crawford, in this issue). This work is reminiscent of the strident examination of what is meant by a bicultural relationship that occurred in the 1980s. In this article, Crawford reminds practitioners of the need to continually engage with these complex tensions to competently work with Māori.

The following two articles in this special edition consider practitioners' engagement with broader environmental issues. In "Biopolitics, complex systems theory and ecological social work: Conceptualising ways of transitioning to low carbon futures", Uschi Bay provides social work with a way of conceptualising environmental challenges that acknowledges the interconnections between life, environment and politics. To highlight these connections, Bay examines the
Transition Town movement which "aims to address climate change, peak oil and create local communities that are resilient and where people live happier lives despite economic austerity" (Bay, in this issue). Using a biopolitical lens, Bay demonstrates how social work, with its multidimensional analysis of people and systems, can contribute to environmental social movements. This article is unique in its contribution by questioning environmental exigencies at micro, meso and macro levels. Bay locates the responsibility of social work to be proactive in being guardians and protectors of the natural environment. Bay offers practical strategies for how this type of social work can occur.

Continuing on with the environmental theme, John Darroch and Carole Adamson explore the significance of animal-human relationships in disaster contexts. In "Companion animals and disasters: The role of human services organisations", the authors stress that considering "the needs of companion animals can significantly lessen the human and economic impact of disasters" (Darroch \& Adamson, in this issue). Given New Zealand's recent earthquakes, this article is timely and prompts human service organisations to include companion animals in the planning for disaster response. The authors provide a range of practical examples for animal-inclusive planning highlighting the connection between vulnerability and recovery post disaster.

The final article in this edition is from Jane George and Lynne Briggs, "Reducing frequent visits to emergency departments". This work demonstrates how a crosssector research and practice collaboration between a statutory and a non-government organisation can address the needs of a particular client group. This type of collaboration requires a shared vision and robust forms of communication between the partners. Such a model as discussed in this article could well have utility for crosssector research and collaboration between organisations in diverse fields of practice. 
We were reminded when editing these articles that it requires courage to innovate, to take a different pathway from the norm with plenty of invitations along the way to succumb to the dominant discourses and suppress creativity. We hope you enjoy this edition of the journal that includes plenty of examples where a counter discourse to traditional modes of practice and research have been illustrated; where new ideas for living, thinking, learning and doing social work have been offered. We have felt privileged to have this opportunity to prepare this edition for you, and hope that through this reading you might feel inspired to try something new, or engage with the creative spirit within as part of your own social work journey.

\section{References}

Michalos, A. (2005). 'Arts and the quality of life: An exploratory study', Social Indicators Research, 71(1-3), 11-59

Stringer, C. (2016). Worker exploitation in New Zealand: A troubling landscape. Auckland, NZ: Auckland University Business School. Retrieved from http://media.wix.com/ ugd/2ffdf5_28e9975b6be2454f8f823c60d1bfdba0.pdf 